\title{
Crude oil contamination interrupts settlement of coral larvae after direct exposure ends
}

\author{
Aaron C. Hartmann ${ }^{1, *}$, Stuart A. Sandin ${ }^{1}$, Valérie F. Chamberland ${ }^{2,3}$, \\ Kristen L. Marhaver ${ }^{2,4}$, Jasper M. de Goeij ${ }^{5}$, Mark J. A. Vermeij ${ }^{2,3}$ \\ ${ }^{1}$ Scripps Institution of Oceanography, University of California San Diego, La Jolla, CA 92093, USA \\ ${ }^{2}$ Caribbean Research and Management of Biodiversity (CARMABI) Foundation, Piscaderabaai z/n, Willemstad, Curaçao \\ ${ }^{3}$ Aquatic Microbiology, Institute for Biodiversity and Ecosystem Dynamics, University of Amsterdam, 1098 XH Amsterdam, \\ The Netherlands \\ ${ }^{4}$ University of California Merced, Merced, CA 95343, USA \\ ${ }^{5}$ Aquatic Environmental Ecology, Institute for Biodiversity and Ecosystem Dynamics, \\ University of Amsterdam, 1098 XH Amsterdam, The Netherlands
}

\begin{abstract}
Oil spills cause damage to marine wildlife that lasts well past their immediate aftermath. Marine offspring that must settle and metamorphose to reach adulthood may be particularly prone to harm if the legacy of oil exposure interrupts later transitions across life stages. Following an oil spill on Curaçao, we found that oil-contaminated seawater reduced settlement of 2 coral species by $85 \%$ and $40 \%$ after exposure had ended. The effect of contamination on settlement was more severe than any direct or latent effects on survival. Therefore, oil exposure reduces the ability of corals to transition to their adult life stage, even after they move away from oil contamination. This interruption of the life cycle likely has severe consequences for recruitment success in these foundational and threatened organisms. Latent, sublethal, and behavioral effects on marine organisms - as shown in this study-are not commonly considered during oil-spill impact assessments, increasing the likelihood that harm to marine species goes underestimated or unmeasured.
\end{abstract}

KEY WORDS: Oil spills · Coral reefs - Larval settlement - Carry-over effects - Latent effects · Orbicella faveolata $\cdot$ Agaricia humilis $\cdot$ Caribbean

\section{INTRODUCTION}

Unprecedented ecological monitoring after the 1989 Exxon Valdez oil spill and subsequent spills have demonstrated that the damage to marine flora and fauna persists months to years after these events take place (Hose et al. 1996, Bue et al. 1998, Bodkin et al. 2002, Golet et al. 2002, Peterson et al. 2003, Votier et al. 2005, Thorne \& Thomas 2008). The presence of crude oil in the marine environment can be particularly deleterious during the early life stages of many organisms. For example, chronic exposure to residual oil causes long-term harm to eggs and lar-

${ }^{*}$ Corresponding author: aaron.hartmann@gmail.com vae of herring and salmon, as well as to juvenile sea otters and bird chicks (Hose et al. 1996, Bue et al. 1998, Bodkin et al. 2002, Golet et al. 2002). These findings highlight the fact that the full impact of oil spills lasts well past their immediate harm and demonstrate that the lasting effects of crude oil on marine ecosystems can be difficult to detect in impact assessments that occur immediately after spills.

While oil exposure induces sublethal injury in offspring of many taxa, the sublethal consequences of oil exposure to marine offspring have been most extensively considered among fishes. For example, larval fishes exposed to oil can manifest decreased

(C) The authors 2015. Open Access under Creative Commons by Attribution Licence. Use, distribution and reproduction are unrestricted. Authors and original publication must be credited. 
cardiac function and other physiological abnormalities (Hicken et al. 2011, de Soysa et al. 2012, Incardona et al. 2012, Whitehead et al. 2012, Incardona et al. 2013, 2014). While the rapid increase in abundance of physiologically disadvantaged offspring following an oil spill may be common (Heintz et al. 2000, Hicken et al. 2011, Incardona et al. 2014), the dispersive nature of marine larvae makes it difficult to connect larval oil exposure to reduced recruitment and declining adult populations. Yet, the full demographic impacts of oil exposure on recruitment success can only be estimated after considering the immediate effects on offspring survivorship as well as the legacy effects of oil after individuals move away from direct exposure.

The life cycle of many marine invertebrates (e.g. corals) includes a mobile dispersal period near the sea surface followed by movement to the seafloor to settle and metamorphose into a sessile adult form. Much like fishes, coral larvae are sensitive to oil contamination and can experience decreased survival and settlement during exposure to crude oil and dispersants (Epstein et al. 2000, Negri \& Heyward 2000, Goodbody-Gringley et al. 2013). In addition, the interruption of critical settlement behaviors and metamorphoses in corals can halt individuals from progressing to adulthood and ultimately prevent recruitment. Thus, marine organisms with complex life histories may be particularly prone to harm from oil contamination if exposure prevents transitions between life stages in addition to causing mortality. Dispersal or downward migration of invertebrate larvae may remove them from areas of high oil concentrations. However, whether the legacy of oil exposure influences the progression to adulthood after larvae move away from oil-contaminated seawater has not yet been examined. Furthermore, the rapid progression of invertebrate offspring from the larval to the settlement period (days to weeks for most corals) provides a useful opportunity to assess: (1) whether the legacy of oil exposure persists after invertebrate larvae move away from contaminated seawater, and (2) whether the legacy of oil exposure interrupts settlement of organisms with complex life histories, in addition to (or instead of) causing mortality.

On August 16, 2012, crude oil was spilled into surface ocean waters near a land-based oil transshipment facility on the southern coast of the Caribbean island of Curaçao. In total, $2.5 \mathrm{~km}$ of coastline were directly affected by oiling (Fig. 1). The spill occurred during a period of larval production for many shallow-water brooding coral species, such as Agaricia humilis, and $3 \mathrm{wk}$ prior to the mass spawning of a

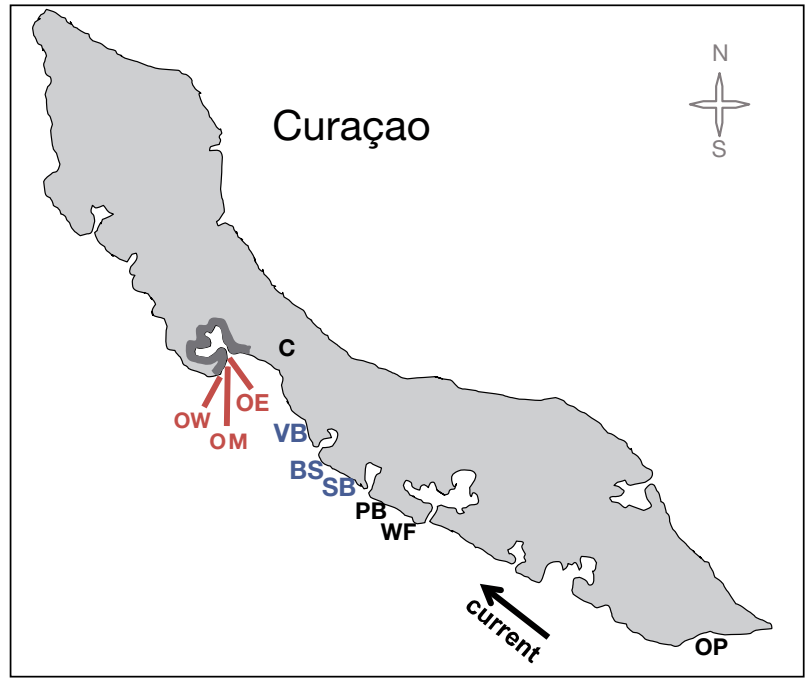

Fig. 1. The extent of coastline and inland bay at Jan Kok, Curaçao, that was oiled in August 2012 (dark gray area), the source of crude oil (C), the 6 sites (red: oiled; blue: nonoiled) at which seawater was collected for larval exposure experiments (OW: Oil West; OM: Oil Middle; OE: Oil East; VB: Vaersenbaai; BS: Boka Sami; SB: Snake Bay), and the site from which non oil-contaminated seawater was collected for larval post-exposure experiments (PB: Piscaderabaai). Also shown are the Water Factory (WF) and Oostpunt (OP) sites from which corals and gametes were collected as sources of Agaricia humilis and Orbicella faveolata larvae that were used in experiments

number of broadcasting coral species (Van Moorsel 1983, Szmant 1986, de Graaf et al. 1999) including Orbicella faveolata, a species recently listed as 'threatened' under the US Endangered Species Act (National Oceanic and Atmospheric Administration 2014). Oil spills and chronic oil pollution have caused declines in adult coral abundance in shallow tropical (Bak 1987, Guzmán et al. 1991, reviewed in Haapkylä et al. 2007) and deepwater ecosystems (White et al. 2012, Fisher et al. 2014). The recovery of coral communities following oil spills is likely hampered by reduced fecundity, larval mortality, and larval settlement failure in response to direct exposure to crude oil (Rinkevich \& Loya 1979, Epstein et al. 2000, Negri \& Heyward 2000). In the wake of the Curaçao oil spill and $2 \mathrm{~d}$ after the spawning of $O$. faveolata, we conducted 2 experiments to determine whether oilcontaminated surface waters affected survival or settlement of $O$. faveolata and $A$. humilis larvae in a direct (during exposure), carry-over (during and after exposure), or latent (only after exposure) manner (Pechenik 2006). Assessing both the direct and delayed consequences of oil contamination across multiple life stages allowed us to quantify the full effect of oil exposure on coral offspring, a necessity 
because oil-induced disruption of any life stages preceding recruitment likely compounds the damage done by oil spills to these already threatened taxa.

\section{MATERIALS AND METHODS}

\section{Oil spill in Jan Kok Bay, Curaçao}

On August 16, 2012, crude oil was spilled into the ocean near the land-based oil transshipment facility at Bullenbaai $\left(12^{\circ} 11^{\prime} 35^{\prime \prime} \mathrm{N}, 69^{\circ} 2^{\prime} 14^{\prime \prime} \mathrm{W}\right)$ on the leeward coast of the island of Curaçao (Figs. 1 \& 2). Approximately $2.5 \mathrm{~km}$ of coastline with adjacent reefs and a large inland bay (Jan Kok) were soiled with crude oil. Cleaning efforts began immediately and lasted until the first week of September 2012. During most of this period, oil continued to seep over nearby reefs, either via flushing out of the bay where it had previously accumulated or by being washed back into the ocean from depressions, rock beds and tide pools during periods of increased wave activity or rain.

\section{Collection of coral larvae}

Colonies of Agaricia humilis were collected from the Water Factory and Oostpunt reefs ( $\mathrm{n}=20$ per site) on the leeward coast of Curaçao (Fig. 1). Both sites are up-current of, and therefore unaffected by, the oil spill. Within $1 \mathrm{~h}$ of collection, corals were placed in
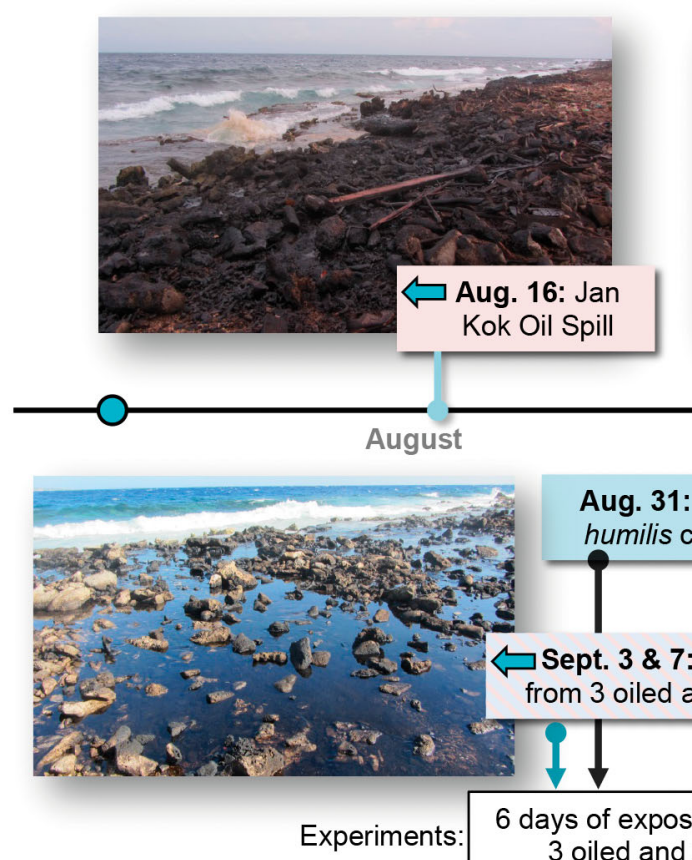

Experiments:
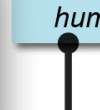

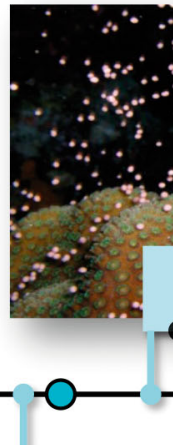

Aug. 31: Agaricia humilis collection

Sept. 3 \& 7: Seawater collected from 3 oiled and 3 non-oiled sites

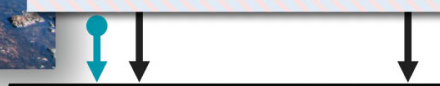

6 days of exposure to seawater from 3 oiled and 3 non-oiled sites

faveolata Orbicella $\widehat{\}}$ faveolata spawning

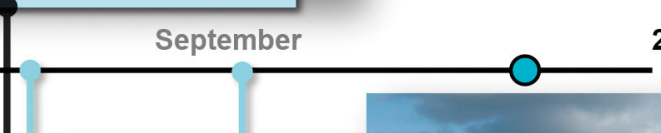
2012

Sept. 10 \& 14: Seawater collected from a common, non-oiled site

\section{$\Rightarrow$}

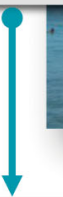

10 days of post-exposure to seawater from a common, non-oiled site and settlement cues
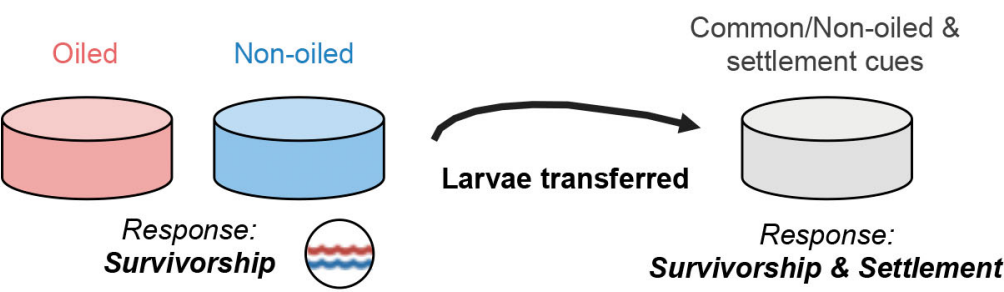

Common/Non-oiled \& settlement cues Survivorship \& Settlement

Fig. 2. Timeline of events beginning with the August 16, 2012, oil spill at Jan Kok Bay, Curaçao (southern Caribbean), followed by the collection of Agaricia humilis larvae and Orbicella faveolata gametes. The $1 \mathrm{~d}$ old larvae were exposed for $6 \mathrm{~d}$ to seawater collected from 3 oil-contaminated and 3 non-contaminated sites. This experiment is depicted in subsequent figures by the circle logo containing red and blue waves. After this period, larvae were transferred to seawater collected from a single, non-contaminated site to which they were exposed for $10 \mathrm{~d}$. Settlement cues were added to assess settlement potential after oil exposure. This experiment is depicted in subsequent figures by the circle logo containing grey waves 
separate 11 beakers with a constant flow of $100 \mu \mathrm{m}$ filtered seawater. All competent larvae released during 1 night were pooled to create a single-age experimental cohort for immediate use. Results are reported for larvae collected from both sites. Gametes of Orbicella faveolata were collected during the broadcast spawning event on September 6, 2012, at the Water Factory site. Gametes from 8 colonies were pooled and allowed to fertilize for $120 \mathrm{~min}$, after which developing embryos were reared following methods described previously (Vermeij et al. 2006). Both species produce non-feeding larvae and O. faveolata larvae tend to have longer larval durations, as is common in broadcast spawning species relative to brooding species (Van Moorsel 1983, Szmant 1986, de Graaf et al. 1999).

\section{Exposure to seawater collected from oil spill sites}

A. humilis and $O$. faveolata larvae were reared for $6 \mathrm{~d}$ in seawater collected on Days 18 and 21 after the oil spill, respectively; therefore, larvae of each species were $1 \mathrm{~d}$ old when their respective experiments began (Fig. 2). Seawater was collected from 3 sites that were directly affected by the oil spill and 3 sites that were not affected by the spill. The seawater collection sites were as follows: Oil West, Oil Middle, and Oil East ( 3 sites along the coastline that was directly soiled by the oil spill, along the coast of Rif Sint Marie, west of Bullenbaai) and Vaersenbaai, Boka Sami, and Snake Bay (3 nearby sites up-current of, and therefore outside, the oil spill; Fig. 1). The concentration of crude oil hydrocarbons (as total mineral oil) was quantified in the field-collected seawater used for larval experiments by the Omegam laboratory (Amsterdam, The Netherlands; see Supplement 1 at www.int-res.com/articles/suppl/ m536p163_supp.pdf for analysis details).

Field seawater was collected approximately $5 \mathrm{~m}$ offshore less than $24 \mathrm{~h}$ before the start of each experiment. Field-collected seawater was filtered $(100 \mu \mathrm{m}$ pore size Nitex mesh) prior to experimental use to remove relatively large debris and zooplankton so that the effect of oil contamination was tested when bacteria and other microorganisms were still present. Acid-washed glass scintillation vials containing $15 \mathrm{ml}$ of seawater were used for all direct exposure experiments, with 8 or 9 replicates per site for O. faveolata and 11 or 12 replicates for A. humilis. Each vial contained $15 \mathrm{O}$. faveolata or $10 \mathrm{~A}$. humilis larvae $\left(O\right.$. faveolata: 1 larva $\mathrm{ml}^{-1}$; $A$. humilis: 0.67 larva $\mathrm{ml}^{-1}$ ) to minimize density effects (Vermeij et al. 2009). This experiment provided a measure of the direct effects of oil-contaminated seawater collected in the field on larval survival and settlement. In order to evaluate the capacity of each site to sustain a coral community, we estimated the percentage of live scleractinian coral at each of the 6 sites at $5 \mathrm{~m}$ depth from photoquadrat images taken by SCUBA divers ( $\mathrm{n} \geq 20$ images per site).

\section{Exposure to seawater artificially contaminated with crude oil}

In order to test for the effects of crude oil in isolation of all other factors, $O$. faveolata and A. humilis larvae were reared for $6 \mathrm{~d}$ in scintillation vials containing filter-sterilized seawater that was artificially contaminated with crude oil obtained from the storage facility at which the oil spill occurred. This crude oil was from the Lake Maracaibo region of Venezuela and has characteristics of a light crude (see Supplement 1 for the distribution of light and heavy carbon chains). Using the method of Epstein et al. (2000), we isolated the water-soluble fraction of crude oil by adding $150 \mathrm{ml}$ of crude oil to $1 \mathrm{l}$ of filter-sterilized seawater (SSW; $0.022 \mu \mathrm{m}$ Sterivex filter) and mixing this solution with a magnetic stirrer for $6 \mathrm{~h}$. After this, the visible oil top layer was removed with a pipette, followed by the removal of an additional approximately $100 \mathrm{ml}$ of water from the surface of the solution to ensure removal of any residual non-dissolved oil. The results here represent the effects of the soluble fraction of crude oil, since we reduced microbial sources of coral mortality by pre-filtering the laboratory-contaminated seawater. Moreover, the dissolved fraction of hydrocarbons is that most likely to remain in nearshore waters $3 \mathrm{wk}$ after the spill.

Larvae were exposed to a simulated gradient of oil contamination by diluting the water-soluble oilcontaminated seawater with non-contaminated SSW to final proportions of: undiluted, $3,10^{1}, 10^{2}, 10^{3}$, and $10^{4}$ diluted. The concentration of total mineral oil in the undiluted, laboratory-contaminated seawater was quantified by the Omegam laboratory (Amsterdam, The Netherlands; see Supplement 1 for analytical details). Each vial contained 15 O. faveolata or 10 A. humilis larvae (the same as in the field-collected seawater experiment) and 5 replicates were used per dilution level for each species. This experiment allowed us to measure the direct effects of a broad range of concentrations of the water-soluble fraction of crude oil on larval survival. 


\section{Post-exposure survival and settlement experiment}

After both experiments described in the previous sections, larvae from each replicate were binned by the field-collected seawater site or concentration level to which they were exposed, and then subsequently re-allocated into Petri dishes. Five replicates for $O$. faveolata and 10 replicates for $A$. humilis were generated for the field-collected seawater experiments, and 4 replicates per dilution level were generated for both species for the laboratory-generated, oil-contaminated seawater experiments. Each Petri dish contained $100 \mu \mathrm{m}$-filtered seawater collected at the Piscaderabaai site $\left(12^{\circ} 7^{\prime} 20^{\prime \prime} \mathrm{N}, 68^{\circ} 58^{\prime} 10^{\prime \prime} \mathrm{W}\right)$, which is approximately $10 \mathrm{~km}$ up-current from the oil spill site and thus was not contaminated by the spill (Figs. 1 \& 2). The number of larvae per replicate was 15 for $O$. faveolata and 10 for $A$. humilis (equal to that used in the initial experiment). Given the higher volume of the Petri dishes relative to the scintillation vials used during the exposure experiment, the water volume for this experiment was increased to $35 \mathrm{ml}$. To induce larval settlement, an extract of crustose coralline algae (to $O$. faveolata replicates) or a cured limestone tile with growing crustose coralline algae (to A. humilis replicates) was added to each replicate. We have previously demonstrated the suitability of these techniques for testing settlement competence in these species (Hartmann et al. 2013). Moving larvae from oil-contaminated to non-oil-contaminated seawater and exposing them to positive settlement cues was done to mimic the migration of larvae from the sea surface to the benthos in search of settlement substrate. Larval survival and settlement were scored for $10 \mathrm{~d}$. This experiment provided a measure of the carry-over and latent effects of exposure to oil contamination on larval survival, as well as the postexposure settlement responses of both species.

During the field-collected seawater post-exposure experiment, a small number $(13 \%)$ of the $A$. humilis replicates exhibited total mortality of swimming larvae but not settled individuals by Day 10. These 'crashes' have previously been observed in this species using a similar experimental method (Hartmann et al. 2013). The likelihood that a replicate crashed in our experiment was independent of site or the presence of oil contamination ( $p>0.05$ for both, Fisher's exact test), suggesting total mortality of larvae was not a response to our treatments. For this reason and because these data violated the assumption of independence of individuals, all replicates in which larvae crashed were removed prior to further statistical tests and data representations of larval survival. As the settled individuals in these replicates survived to the end of the experiment, they were included in our reported estimations of settlement success. We also estimated settlement success excluding the replicates that crashed for the purposes of comparison. A larger proportion ( $>60 \%$ ) of $A$. humilis larvae died by Day 3 of the laboratory-generated, oil-contaminated seawater post-exposure experiment (i.e. Day 10 of experimentation) and this experiment was ended. This outcome perhaps highlights a high level of sensitivity in this species to long-term laboratory survivorship experiments.

\section{Statistical analyses}

Comparisons of survival and settlement among field seawater sites were made using a maximum likelihood approach to determine relative fits of candidate models to the observed data (Hilborn \& Mangel 1997). For each experiment, a statistical replicate was considered to be the number of larvae alive (for survivorship) or settled (for settlement) relative to the number of larvae alive at the beginning of the experiment in an individual dish. In addition, settlement was modeled relative to the total number of larvae that survived to the end of a given experiment. The probability that an individual larva survived or settled within a replicate dish was assumed to be independent of the fate of all other individuals in the dish, and thus variation across larvae within a dish was modeled following a binomial error distribution. In order to test whether treatment level (with and without exposure to oil) affected the probability of survival or settlement, the relative fit of a 2-parameter model $([\mathrm{OW}=\mathrm{OM}=\mathrm{OE}] \neq[\mathrm{VB}=\mathrm{BS}=\mathrm{SB}]$; see Fig. 1 for site names) was compared to the 1-parameter model (all probabilities equal across sites) using a likelihood ratio test (LRT; see Supplement 2 at www.int-res.com/articles/suppl/m536p163_supp.pdf). Exploring the post hoc patterns of variation across sites, the most parsimonious combination of survivorship or settlement probabilities among field seawater sites was determined by comparing the relative fit of all possible model structures (ranging from $1 \mathrm{com}$ mon probability across all 6 sites to 6 independent probabilities, and including all combinations of 2, 3, 4 , and 5 parameter models). The most supported parameter values within each model were determined using maximum likelihood. The best-fit model among the candidate models (from 1 to 6 parameters) was determined by comparing the relative maximum likelihood values of all models using Akaike's infor- 
mation criterion (AIC). In order to determine whether the best-fit model among models with equal numbers of parameters was statistically distinct from others within this group, an assumption of equal Bayesian prior probability was made and the model was determined statistically distinct if the posterior probability of the model was less than 0.05 (Vermeij \& Sandin 2008, Marhaver et al. 2013). The survival and settlement of larvae in response to a dilution series of laboratory-generated, oil-contaminated seawater were evaluated using logistic regression. The probability of survival or settlement was related to the $\log _{10^{-}}$ transformed proportional amount of oil-contaminated seawater used in each level of the dilution series. Best-fit logistic models are presented when they performed better than the null hypothesis of constant probability across treatment levels. We employed the pseudo- $\mathrm{R}^{2}$ approach of McFadden (1974) to report the relative fits of the logistic regression models.

\section{RESULTS}

During exposure to seawater from 3 sites within the oil-contaminated region, larvae of the broadcastspawning Caribbean coral Orbicella faveolata suffered a $10 \%$ reduction in survival compared to nonoiled sites $(p<0.05$, LRT between a priori model structures; Fig. 3A, see Table S6 in Supplement 2 at www.int-res.com/articles/suppl/m536p163_supp.pdf). Meanwhile, this species showed no survivorship response across 6 concentrations of laboratory-generated, oil-contaminated seawater during the exposure period ( $p>0.05$; Fig. 3E, see Table S10 in Supplement 2). The crude oil hydrocarbon concentration (as total mineral oil) in seawater collected from the Oil West site for the Agaricia humilis experiments (Day 18 after the spill) was $145 \mu g \mathrm{l}^{-1}$. The measured concentration at the same site was $135 \mu \mathrm{g} \mathrm{l}^{-1}$ when seawater was collected for $O$. faveolata experiments 3 d later (Day 21 following the oil spill).

Survivorship after exposure to oil-contaminated and non oil-contaminated seawater

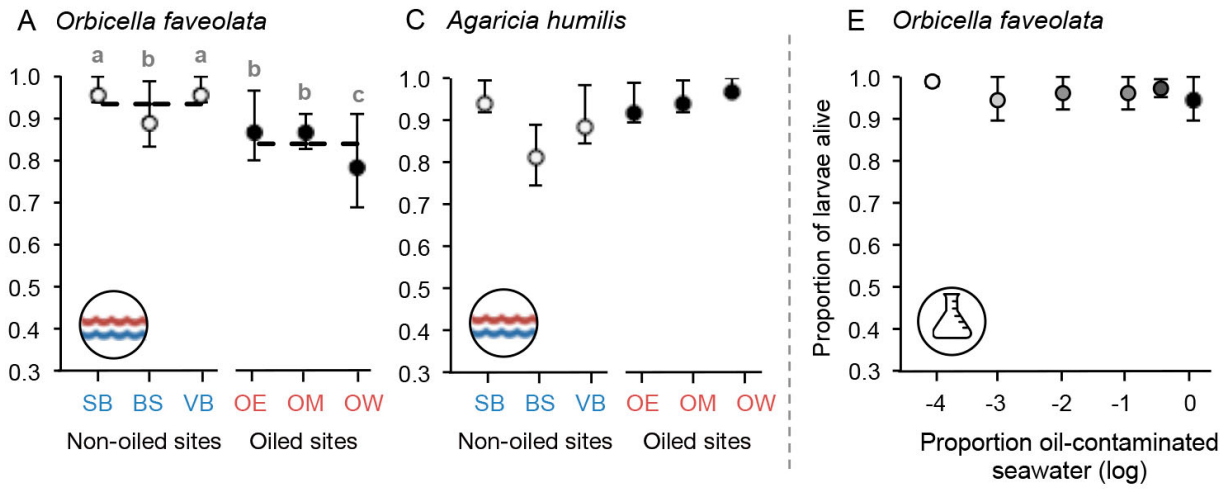

Survivorship after post-oil exposure to common, non oil-contaminated seawater and settlement cues
D Agaricia humilis

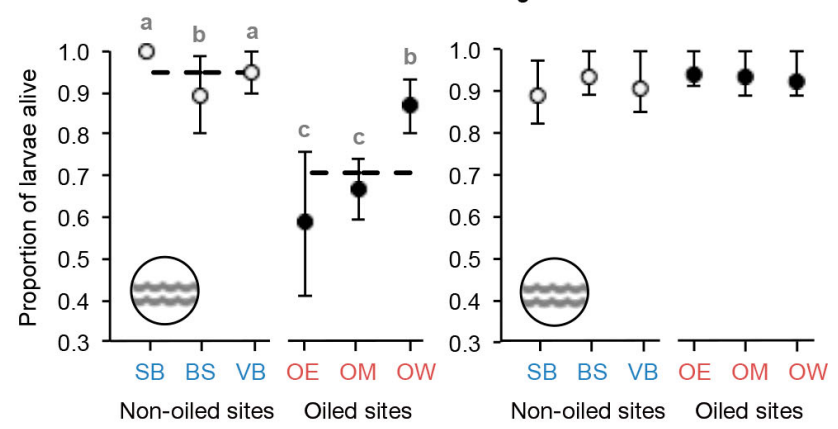

F Orbicella faveolata

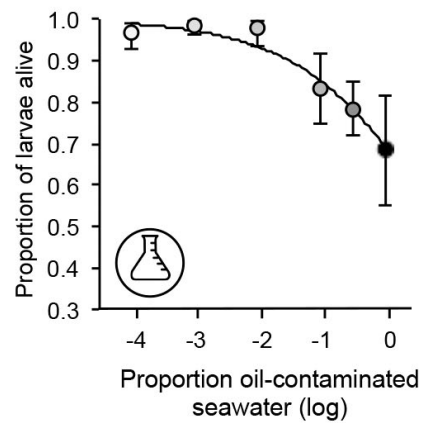

G Agaricia humilis

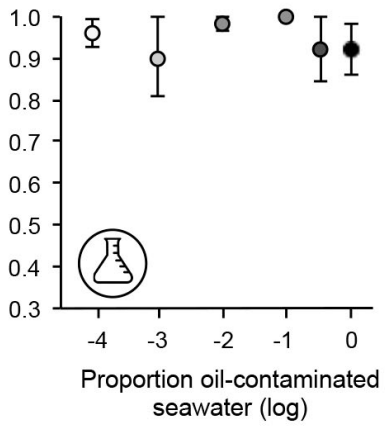

Fig. 3. Mean survivorship of (A) Orbicella faveolata and (C) Agaricia humilis larvae after 6 d of exposure to seawater collected from the 3 oiled and 3 non-oiled sites, followed by $10 \mathrm{~d}$ of exposure to seawater from a common, non-oiled site (B and D, respectively). Error bars represent arcsine square root-transformed $95 \%$ confidence intervals. Letters above each bar represent significant differences between sites $(\mathrm{A}-\mathrm{D} ; \alpha=0.05)$. Mean survivorship of (E) $O$. faveolata and (G) A. humilis larvae after $6 \mathrm{~d}$ of exposure to laboratory-generated, oil-contaminated sterile seawater, followed by $10 \mathrm{~d}$ of exposure to seawater from a common, non-oiled site ( $\mathrm{F}$ and $\mathrm{H}$, respectively). Logistic regression fits are shown for statistically significant relationships $(\mathrm{E}-\mathrm{H} ; \alpha=0.05)$. For definitions of site abbreviations and circle logos in A to D, see Figs. 1 \& 2, respectively. Circle logos in $\mathrm{E}$ to $\mathrm{H}$ denote the use of laboratory-generated, oil-contaminated seawater in those experiments

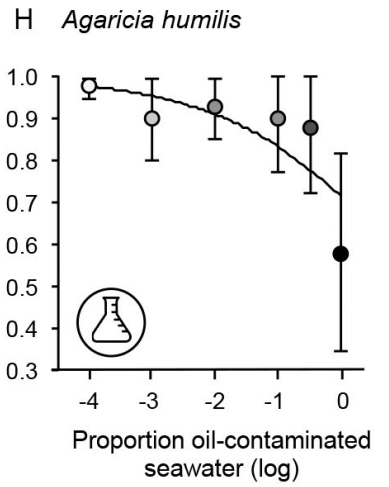


After these experiments, larvae from all treatments were transferred to non-contaminated seawater to mimic movement away from oil-contaminated seawater. After $10 \mathrm{~d}$ in non-contaminated seawater, survival was $25 \%$ lower in $O$. faveolata larvae that were previously exposed to seawater from the oiled sites compared to the non-oiled sites $(\mathrm{p}<0.05$, LRT model fit; Fig. 3B, see Table S7 in Supplement 2). This postexposure mortality demonstrates that exposure to oil-contaminated seawater affected larval survival most severely after, rather than during, exposure. Similarly, for larvae previously exposed to laboratory-generated, oil-contaminated seawater, postexposure survival decreased with increasing concentrations of oil contamination $\left(\mathrm{p}<0.001\right.$, pseudo- $\mathrm{R}^{2}=$ 0.38 , logistic regression; Fig. 3F, see Table S10 in Supplement 2). The undiluted laboratory-contaminated seawater contained $550 \mu \mathrm{g} \mathrm{l}^{-1}$ total mineral oil, which was approximately 4 times higher than the concentration measured in the field-collected seawater (see above paragraph: 135 to $145 \mu \mathrm{g} \mathrm{l^{-1 }}$ ). Based on the dilution factors, the respective concentrations of mineral oil in our dilution series were approximately 550, 182, 55, 5, 0.5, and $0.05 \mu \mathrm{g} \mathrm{l^{-1 }}$. The dissolved crude oil fraction showed patterns consistent with a light crude, as it was largely depleted in the longestcarbon-chained fractions: C10-C19 = 30\%, C19$\mathrm{C} 29=51 \%, \mathrm{C} 29-\mathrm{C} 35=17 \%$, and C35-C40 = 2\% (see Supplement 1).

During exposure, larvae of the brooding coral A. humilis exhibited no differences in survivorship between oil-contaminated and non-oil-contaminated seawater collection sites or in increasing concentrations of laboratory-generated, oil-contaminated seawater ( $p>0.05$ for both, LRT model fit; Fig. 3C,G, respectively, see Tables S2 \& S10, respectively, in Supplement 2). However, this species did experience latent mortality in response to laboratory-generated oil-contaminated seawater. Until Day 2 of the postexposure experiment, larval survival decreased with increasing concentration of the oil contamination to which they were previously exposed $(\mathrm{p}<0.001$, pseudo- $\mathrm{R}^{2}=0.21$, logistic regression; Fig. $3 \mathrm{H}$, see Table S10). However, across dilutions, over $60 \%$ of the A. humilis larvae died in this experiment by Day 3 and the experiment was ended (see 'Materials and methods: Post-exposure survival and settlement experiment' for details). Therefore, data shown in Fig. $3 \mathrm{H}$ reflect Day 2 of the experiment instead of Day 10 .

In order to assess the effect of oil contamination on settlement success, coral larvae were offered settlement cues after they were moved from oil-contami- nated seawater to non-contaminated seawater. After $10 \mathrm{~d}$ in non-contaminated seawater, O. faveolata larvae previously exposed to oil-contaminated seawater had $85 \%$ lower settlement than larvae previously exposed to seawater from the non-contaminated sites ( $p<0.001$, LRT model fit; Fig. 4A, see Table S8 in Supplement 2). Settlement was highest among larvae previously exposed to seawater from the non-oiled Snake Bay site $(54 \%)$, intermediate among those exposed to seawater from the non-oiled Boka Sami and Vaersenbaai sites (32\% and 29\%, respectively) and lowest in those exposed to seawater from the 3 oiled sites $(9 \%, 4 \%$, and $4 \%)$. These 3 groupings of treatments best described the data $(\mathrm{p}<0.05$ relative to next best-fit model of equal parameters, see Table S8). Settlement also declined in response to previous exposure to increasing concentrations of laboratory-generated, oil-contaminated seawater $(\mathrm{p}<$ 0.001, pseudo- $\mathrm{R}^{2}=0.41$, logistic regression; Fig. 4C, see Table S10 in Supplement 2). Similar patterns emerged when settlement success was modeled relative to the number of larvae surviving the experiment rather than the number of larvae that began the experiment (see Tables S9 \& S10). Settlement was highest among larvae previously exposed to seawater from the non-oiled Snake Bay site (54\%), intermediate in those exposed to seawater from the nonoiled Boka Sami and Vaersenbaai sites (36\% and $31 \%$, respectively) and lowest in those exposed to seawater from the 3 oiled sites $(14 \%, 7 \%$, and $5 \%$ ). Settlement also declined in response to previous exposure to increasing concentrations of oil-contaminated seawater $\left(\mathrm{p}<0.001\right.$, pseudo- $\mathrm{R}^{2}=0.36$, logistic regression; see Table $\mathrm{S} 10)$.

Similarly to O. faveolata, A. humilis larvae suffered a reduction in settlement after being exposed to oilcontaminated seawater. Larvae exposed to seawater from the 3 oiled sites had $40 \%$ lower settlement than larvae exposed to seawater from the non-oiled sites ( $p<0.05$, LRT model fit; Fig. 4B, see Table S4 in Supplement 2). Settlement was higher after larvae experienced seawater from the non-oiled Snake Bay and Vaersenbaai sites (44\% and $32 \%$, respectively) compared to Boka Sami (13\%) and the 3 oiled sites (20\%, $20 \%$, and $13 \%, p<0.05$ relative to next best-fit model of equal parameters, see Table S4). When replicate dishes exhibiting total mortality of swimming larvae but not settlers were excluded from settlement estimations, the estimated proportion of larvae settling after exposure to seawater from the non-oiled sites Boka Sami and Vaersenbaai decreased to $3 \%$ and $28 \%$, respectively, with no change among other sites. Settlement of A. humilis 
Settlement after post-oil exposure to common, non oil-contaminated seawater and settlement cues
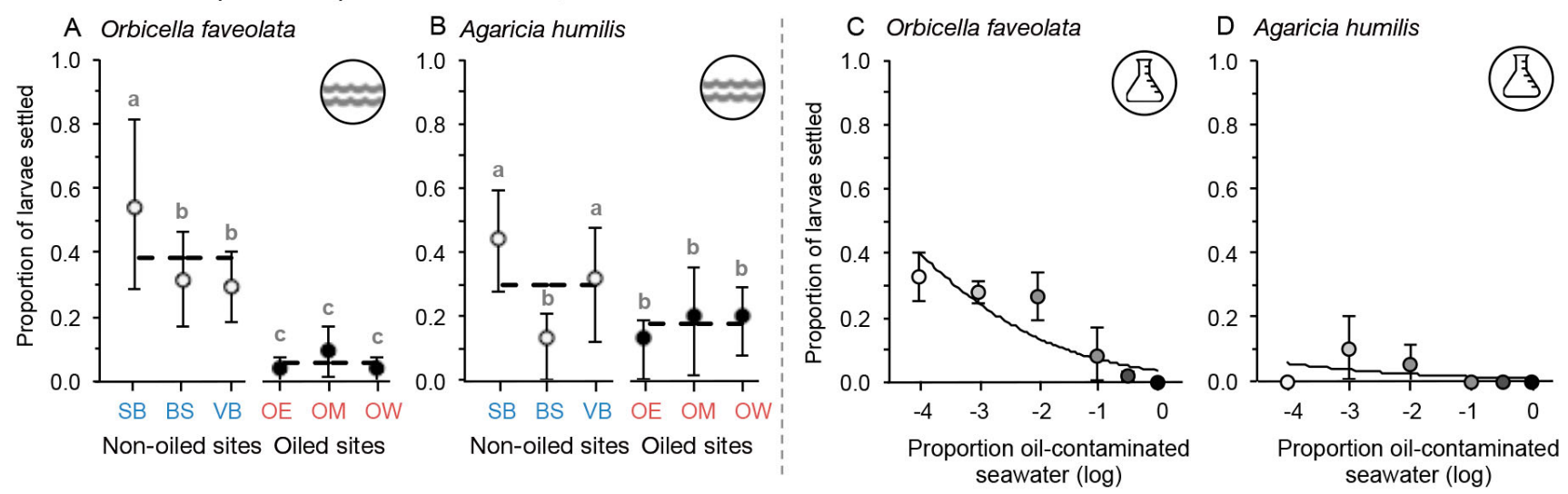

Fig. 4. Mean settlement of (A) Orbicella faveolata and (B) Agaricia humilis larvae after 10 d of exposure to seawater from a single, non oil-contaminated site, following $6 \mathrm{~d}$ of exposure to seawater collected from 3 oiled and 3 non-oiled sites. Error bars represent arcsine square root-transformed $95 \%$ confidence intervals. Letters above each bar represent significant differences between sites $(\mathrm{A}, \mathrm{B} ; \alpha=0.05)$. Mean settlement of (C) O. faveolata larvae after $10 \mathrm{~d}$ and (D) A. humilis larvae after $2 \mathrm{~d}$ of exposure to non oil-contaminated seawater, which followed $6 \mathrm{~d}$ of exposure to laboratory-generated, oilcontaminated sterile seawater. Logistic regression fits are shown for statistically significant relationships $\left(C, D_{;} \alpha=0.05\right)$. See Fig. 1 for site abbreviations

larvae declined with previous exposure to increasing concentration of laboratory-generated, oil-contaminated seawater $\left(\mathrm{p}<0.05\right.$, pseudo- $\mathrm{R}^{2}=0.09$, logistic regression; Fig. 4D, see Table S10). Patterns were similar when settlement success was modeled relative to the number of larvae surviving the experiment rather than the number of larvae that began the experiment (see Tables S5 \& S10). Settlement was highest following exposure to seawater from the nonoiled Snake Bay site (57\%), intermediate after exposure to seawater from the non-oiled Vaersenbaai site $(32 \%)$, lower after exposure to seawater from the 3 oiled sites $(23 \%, 23 \%$, and $12 \%)$, and lowest following exposure to seawater from the Boka Sami site $(1 \%)$. The apparent drop in settlement after exposure to Boka Sami seawater resulted from the necessary exclusion of relatively high-settlement replicates in which swimming larvae crashed (described in 'Materials and methods: Post-exposure survival and settlement experiment'). When compared to the number of surviving larvae, settlement success no longer showed a significant decrease with previous exposure to increasing concentrations of oil-contaminated seawater $\left(p>0.05\right.$, pseudo- $R^{2}=0.06$, logistic regression; see Table S10).

\section{DISCUSSION}

Exposure to crude oil contamination has negative carry-over and latent effects on larval survival in corals, effects that demographically outweighed the direct effects of exposure in our experiments. Crude oil and oil dispersants can reduce the survival and settlement of coral larvae during exposure (Epstein et al. 2000, Goodbody-Gringley et al. 2013) and may lower recruitment rates onto reefs that have suffered from months of chronic crude oil inputs (Negri \& Heyward 2000). Our results show that oil contamination-induced larval mortality in corals is not limited to mortality during the exposure period, highlighting the fact that the carry-over and latent effects of oil exposure on invertebrate larvae deserve attention when assessing the ecological damage from oil spills.

The legacy of oil exposure on settlement rates in 2 species of corals provides further evidence that this life stage is highly sensitive to environmental conditions, even when those conditions were experienced prior to the settlement and metamorphosis stage (i.e. during dispersal; Vermeij et al. 2006, Hartmann et al. 2013, Ross et al. 2013). While the effect of oil contamination on survival reduced coral populations by $25 \%$ in Orbicella faveolata and undetectably in Agaricia humilis, inclusion of the effect of oil on total settlement reduced coral densities by $85 \%$ and $40 \%$, respectively. Thus, while survival is a commonly used metric to quantify the effects of various toxins, we find that behaviors such as settlement can carry a much stronger signature of toxin exposure encountered earlier in life. Using similar concentrations of dissolved crude oil, Negri \& Heyward (2000) found that direct exposure decreased coral settlement more 
than survival. Consequently, exposure to oil-contaminated seawater caused a dramatic reduction in the likelihood that swimming coral larvae could successfully attach to the benthos, a critical stage in reaching their adult form.

Coral cover, i.e. the percentage of the benthos covered in live adult coral, is a widely used indicator of reef status and 'health' (e.g. Jackson et al. 2014). Marine larvae, including corals, are responsive to auditory and chemical cues, both of which can attract larvae toward a reef with high coral cover over a reef with lower coral cover (Vermeij et al. 2010, Dixson et al. 2014, Lecchini et al. 2014). The effects of highcover versus low-cover reefs on larval performance, however, were unlikely to influence the qualitative settlement patterns of larvae assessed in our study. Mean coral cover was lower at the non-oiled sites $(14 \%)$ relative to the oiled sites $(38 \%$; $p<0.001)$, largely because coral cover was lowest at 2 of the non-oiled collection sites, Vaersenbaai (8\%) and Boka Sami (3\%). Among the 3 non-oiled sites, we found evidence consistent with previous studies that chemical cues attract larvae to high coral cover reefs: O. faveolata settlement was significantly higher after larvae were exposed to seawater from the high cover, non-oiled Snake Bay site (32\% coral cover) relative to the lower cover, non-oiled sites Vaersenbaai (8\% coral cover) and Boka Sami (3\% coral cover; Fig. 4A). Similarly, among the non-oiled sites, settlement of A. humilis larvae was lower after exposure to seawater from the Boka Sami site. Contrasting with this pattern, settlement of $O$. faveolata and A. humilis larvae exposed to field-collected seawater from the oiled sites, which all had relatively high coral cover (35 to $44 \%$ ), was lower than the settlement of larvae exposed to seawater from all 3 non-oiled sites. These results suggest that low, yet detectable, concentrations of crude oil hydrocarbons remaining in seawater at the high coral cover sites masked the positive settlement cues present in the water of these robust reefs.

Taken in sum, our results yield 3 important insights into the effects of crude oil on coral larvae. First, crude oil contamination that remains in surface waters after oil spills can have significant and persistent negative effects on coral larvae. Seawater collected 3 wk after the spill contained only low levels of crude oil hydrocarbons (135 to $145 \mu \mathrm{g} \mathrm{l}^{-1}$; detection limit $100 \mathrm{~g} \mathrm{l}^{-1}$ ) and the consequences of exposure were not detected until over 1 mo after the oil spill occurred. Similarly, negative effects of oil spills on embryonic and adult fish have been identified months later in temperate marine environments, likely arising due to weathering of oil fractions from rocks and sediments (Incardona et al. 2012, Whitehead et al. 2012).

Second, the effect of trace oil contamination on larvae is not always evident during the exposure period. In our experiments, the legacy of exposure to oilcontaminated seawater had negative carry-over and latent effects on larvae of both species. For all indicators, these delayed effects outweighed direct effects, showing that even after larvae escape contaminated seawater the impact of chemical stressors remains. While the larval period constitutes a short period in the life of organisms such as corals, the environment experienced during these early stages has a disproportionately large effect on the long-term success of these individuals (Vermeij et al. 2006, Hartmann et al. 2013, Ross et al. 2013).

Third, the fact that oil contamination had a larger impact on coral settlement than on survival suggests that oil contamination interrupts the coral life cycle even after exposure ends and often in a sublethal manner. The inability of coral larvae to settle after exposure to toxins may in part be responsible for previous recruitment failures despite large broadcastspawning events in areas with chronic human impacts (Szmant 1991, Hughes \& Tanner 2000, Vermeij et al. 2011). The ability of damaged coral communities to recover from an oil spill is in part dependent on the successful recruitment of offspring in the months to years that follow. Contamination-induced interruption of larval settlement suggests that traditional metrics of toxicity (e.g. $\mathrm{LD}_{50}$ ) underestimate the true impact of oil spills on marine organisms, especially those organisms that go through environmentally sensitive life stages such as settlement and metamorphosis. Environmental impact assessments must therefore take into consideration the great potential for post-exposure, sublethal, and behavioral effects on marine organisms rather than focusing solely on direct and immediate effects.

Acknowledgements. We thank the staff of CARMABI Foundation and DiveVersity for their assistance with field logistics. We thank Nancy Knowlton and 3 anonymous reviewers for their thoughtful suggestions on improving the manuscript. This work was supported by the National Science Foundation (NSF) Graduate Research Fellowship Program (A.C.H.) and the PADI Foundation (A.C.H.), by NSF grant Nos. IOS1146880 and OCE1323820 (K.L.M.), by the Government of Curaçao and funding from the European Union 7 th Framework Programme (P7/2007-2013) under grant No. 244161 (M.J.A.V.), and by the Innovational Research Incentives Scheme of the Netherlands Organization for Scientific Research (NWO-VENI; 863.10.009; personal grant to J.M.deG.). Funders had no influence on the design, interpretation, or publication of this research. 


\section{LITERATURE CITED}

Bak RPM (1987) Effects of chronic oil pollution on a Caribbean coral reef. Mar Pollut Bull 18:534-539

$>$ Bodkin JL, Ballachey BE, Dean TA, Fukuyama AK and others (2002) Sea otter population status and the process of recovery from the 1989 'Exxon Valdez' oil spill. Mar Ecol Prog Ser 241:237-253

Bue BG, Sharr S, Seeb JE (1998) Evidence of damage to pink salmon populations inhabiting Prince William Sound, Alaska, two generations after the Exxon Valdez oil spill. Trans Am Fish Soc 127:35-43

de Graaf M, Geertjes GJ, Videler JJ (1999) Observations on spawning of scleractinian corals and other invertebrates on the reefs of Bonaire (Netherlands Antilles, Caribbean). Bull Mar Sci 64:189-194

de Soysa TY, Ulrich A, Friedrich T, Pite D and others (2012) Macondo crude oil from the Deepwater Horizon oil spill disrupts specific developmental processes during zebrafish embryogenesis. BMC Biol 10:40

> Dixson DL, Abrego D, Hay ME (2014) Chemically mediated behavior of recruiting corals and fishes: a tipping point that may limit reef recovery. Science 345:892-897

Epstein N, Bak RPM, Rinkevich J (2000) Toxicity of third generation dispersants and dispersed Egyptian crude oil on red sea coral larvae. Mar Pollut Bull 40:497-503

Fisher CR, Hsing PY, Kaiser CL, Yoerger DR and others (2014) Footprint of Deepwater Horizon blowout impact to deep-water coral communities. Proc Natl Acad Sci USA 111:11744-11749

Golet GH, Seiser PE, McGuire AD, Roby DD and others (2002) Long-term direct and indirect effects of the 'Exxon Valdez' oil spill on pigeon guillemots in Prince William Sound, Alaska. Mar Ecol Prog Ser 241:287-304

Goodbody-Gringley G, Wetzel DL, Gillon D, Pulster E, Miller A, Ritchie KB (2013) Toxicity of Deepwater Horizon source oil and the chemical dispersant, Corexit ${ }^{\circledR}$ 9500, to coral larvae. PLoS ONE 8:e45574

Guzmán HM, Jackson JBC, Weil E (1991) Short-term ecological consequences of a major oil spill on Panamanian subtidal reef corals. Coral Reefs 10:1-12

Haapkylä J, Ramade F, Salvat B (2007) Oil pollution on coral reefs: a review of the state of knowledge and management needs. Vie Milieu 57:95-111

> Hartmann AC, Marhaver KL, Chamberland VF, Sandin SA, Vermeij MJA (2013) Large birth size does not reduce negative latent effects of harsh environments across life stages in two coral species. Ecology 94:1966-1976

Heintz RA, Rice SD, Wertheimer AC, Bradshaw RF, Thrower FP, Joyce JE, Short JW (2000) Delayed effects on growth and marine survival of pink salmon Oncorhynchus gorbuscha after exposure to crude oil during embryonic development. Mar Ecol Prog Ser 208: 205-216

> Hicken CE, Linbo TL, Baldwin DH, Willis ML and others (2011) Sublethal exposure to crude oil during embryonic development alters cardiac morphology and reduces aerobic capacity in adult fish. Proc Natl Acad Sci USA 108:7086-7090

Hilborn R, Mangel M (1997) The ecological detective: confronting models with data. Princeton University Press, Princeton, NJ

Hose JE, McGurk D, Marty GD, Hinton DE, Brown ED, Baker TT (1996) Sublethal effects of the Exxon Valdez oil spill on herring embryos and larvae: morphological, cytogenetic, and histopathological assessments, 19891991. Can J Fish Aquat Sci 53:2355-2365

Hughes TP, Tanner JE (2000) Recruitment failure, life histories, and long-term decline of Caribbean corals. Ecology 81:2250-2263

Incardona JP, Vines CA, Anulacion BF, Baldwin DH and others (2012) Unexpectedly high mortality in Pacific herring embryos exposed to the 2007 Cosco Busan oil spill in San Francisco Bay. Proc Natl Acad Sci USA 109: E51-E58

Incardona JP, Swarts TL, Edmunds RC, Linbo TL and others (2013) Exxon Valdez to Deepwater Horizon: Comparable toxicity of both crude oils to fish early life stages. Aquat Toxicol 142-143:303-316

> Incardona JP, Gardner LD, Linbo TL, Brown TL and others (2014) Deepwater Horizon crude oil impacts the developing hearts of large predatory pelagic fish. Proc Natl Acad Sci USA 111:E1510-E1518

Jackson JBC, Donovan MK, Cramer KL, Lam VV (2014) Status and trends of Caribbean coral reefs: 1970-2012. Global Coral Reef Monitoring Network, IUCN, Gland

> Lecchini D, Miura T, Lecellier G, Banaigs B, Nakamura Y (2014) Transmission distance of chemical cues from coral habitats: implications for marine larval settlement in context of reef degradation. Mar Biol 161:1677-1686

Marhaver KL, Vermeij MJA, Rohwer F, Sandin SA (2013) Janzen-Connell effects in a broadcast-spawning Caribbean coral: distance-dependent survival of larvae and settlers. Ecology 94:146-160

McFadden D (1974) Conditional logit analysis of qualitative choice behavior. In: Zarembka P (ed) Frontiers in econometrics. Academic Press, New York, NY, p 105-142

National Oceanic and Atmospheric Administration (2014) NOAA lists 20 new corals as Threatened under the Endangered Species Act. Available at www.fisheries. noaa.gov/stories/2014/08/docs/corals_fact_sheet.pdf (last accessed September 3, 2015)

$>$ Negri AP, Heyward AJ (2000) Inhibition of fertilization and larval metamorphosis of the coral Acropora millepora (Ehrenberg, 1834) by petroleum products. Mar Pollut Bull 41:420-427

Pechenik JA (2006) Larval experience and latent effects metamorphosis is not a new beginning. Integr Comp Biol 46:323-333

Peterson CH, Rice SD, Short JW, Esler D, Bodkin JL, Ballachey BE, Irons DB (2003) Long-term ecosystem response to the Exxon Valdez oil spill. Science 302:2082-2086

> Rinkevich B, Loya Y (1979) Laboratory experiments on the effects of crude oil on the Red Sea coral Stylophora pistillata. Mar Pollut Bull 10:328-330

> Ross C, Ritson-Williams R, Olsen K, Paul VJ (2013) Shortterm and latent post-settlement effects associated with elevated temperature and oxidative stress on larvae from the coral Porites astreoides. Coral Reefs 32:71-79

Szmant AM (1986) Reproductive ecology of Caribbean reef corals. Coral Reefs 5:43-53

Szmant AM (1991) Sexual reproduction by the Caribbean reef corals Montastrea annularis and M. cavernosa. Mar Ecol Prog Ser 74:13-25

Thorne RE, Thomas GL (2008) Herring and the 'Exxon Valdez' oil spill: an investigation into historical data conflicts. ICES J Mar Sci 65:44-50

Van Moorsel GWNM (1983) Reproductive strategies in two closely related stony corals (Agaricia Scleractinia). Mar Ecol Prog Ser 13:273-284 
Vermeij MJA, Sandin SA (2008) Density-dependent settlement and mortality structure the earliest life phases of a coral population. Ecology 89:1994-2004

Vermeij MJA, Fogarty ND, Miller MW (2006) Pelagic conditions affect larval behavior, survival, and settlement patterns in the Caribbean coral Montastraea faveolata. Mar Ecol Prog Ser 310:119-128

Vermeij MJA, Smith JE, Smith CM, Thurber RV, Sandin SA (2009) Survival and settlement success of coral planulae: independent and synergistic effects of macroalgae and microbes. Oecologia 159:325-336

> Vermeij MJA, Marhaver KL, Huijbers CM, Nagelkerken I, Simpson SD (2010) Coral larvae move toward reef sounds. PLoS ONE 5:e10660

> Vermeij MJA, Bakker J, van der Hal N, Bak RPM (2011)

Editorial responsibility: Pei-Yuan Qian,

Kowloon, Hong Kong, SAR
Juvenile coral abundance has decreased by more than $50 \%$ in only three decades on a small Caribbean island. Diversity 3:296-307

Votier SC, Hatchwell BJ, Beckerman A, McCleery RH and others (2005) Oil pollution and climate have widescale impacts on seabird demographics. Ecol Lett 8: 1157-1164

White HK, Hsing PY, Cho W, Shank TM and others (2012) Impact of the Deepwater Horizon oil spill on a deepwater coral community in the Gulf of Mexico. Proc Natl Acad Sci USA 109:20303-20308

Whitehead A, Dubansky B, Bodinier C, Garcia TI and others (2012) Genomic and physiological footprint of the Deepwater Horizon oil spill on resident marsh fishes. Proc Natl Acad Sci USA 109:20298-20302

Submitted: January 9, 2015; Accepted: July 22, 2015

Proofs received from author(s): September 9, 2015 